\title{
Efficacy of a Virtual Education Program for Family Caregivers of Persons Living with Dementia
}

\author{
Margaret A. Noel ${ }^{\mathrm{a}, *}$, Elizabeth Lackey ${ }^{\mathrm{a}}$, Vanna Labi ${ }^{\mathrm{b}}$ and Erin D. Bouldin ${ }^{\mathrm{c}}$ \\ ${ }^{a}$ MemoryCare, Asheville, NC, USA \\ ${ }^{\mathrm{b}}$ Gillings School of Global Public Health, University of North Carolina - Chapel Hill, Asheville, NC, USA \\ ${ }^{\mathrm{c}}$ Department of Health and Exercise Science, Appalachian State University, Boone, NC, USA
}

Handling Associate Editor: Lori Newkirk

Accepted 22 January 2022

Pre-press 25 February 2022

\begin{abstract}
.
Background: Family caregivers of people with dementia often experience negative impacts including stress and burden. Psychoeducational programs can reduce these negative outcomes.

Objective: To evaluate whether this virtual caregiver education program changes caregiver confidence, self-efficacy, and burden relative to controls.

Methods: This was a pre-post comparison of a five-week, synchronous, virtual caregiver education program delivered by a clinician and caregiver support specialist covering aspects of dementia, including changes in cognition, behavior, functional abilities, caregiver-care recipient roles, communication, and caregiver self-care. Caregivers $(n=90)$ were surveyed at baseline, at completion of intervention, and three months thereafter; controls $(n=44)$ were surveyed at two points six weeks apart. We compared validated measures of caregiver confidence, self-efficacy, and burden using generalized estimating equations.

Results: Participants' confidence and self-efficacy increased over follow-up compared with controls $(p<0.01$ for intervention*time in regression models). There was no difference in burden. All participants (100\%) reported perceived increased knowledge, $97 \%$ perceived increased confidence, and 95\% perceived increased ability to manage dementia-related behaviors after the course.

Conclusion: This virtual caregiver education program was effective in improving caregiver confidence and self-efficacy and participants' self-reported impact was equivalent to those who had taken previous courses in person. Caregivers with greater confidence and self-efficacy have been shown to have better health outcomes and decreased stress and depressive symptoms. Health professionals, health care organizations, and public health agencies should consider using efficacious virtual caregiver education programs in rural and other community settings, during public health crises, or in standard practice as an alternative to in-person programs.
\end{abstract}

Keywords: Alzheimer's disease, caregiver education, dementia, health education, internet-based intervention, program evaluation, rural population, self-concept, self efficacy

\section{INTRODUCTION}

${ }^{*}$ Correspondence to: Margaret Noel, MD, MemoryCare, 100 Far Horizons Ln, Asheville, NC 28803, USA. E-mail: noel@ memorycare.org.
Having an engaged, competent family caregiver is a critical social determinant of health for a person living with dementia. Dementia caregiving is a global public health issue with a broad array of both 
positive and negative impacts on the caregiver and the person with dementia [1]. An estimated 11.2 million informal caregivers provide care for someone with Alzheimer's disease or other dementia in the US. Informal caregivers, including family members and friends, are a vital source of care for people living with dementia in community settings [2-4]. Family caregivers of persons living with dementia (hereafter, "caregivers") help with an array of tasks and thereby improve the health and quality of life of their care recipients, sometimes preventing or delaying institutionalization [3, 4]. While having a caregiver can benefit people with dementia, caregiving may negatively impact caregivers themselves by creating stress which can affect them emotionally, physically, and financially, ultimately contributing to poor mental and physical health outcomes $[1,3,5,6]$.

There is ample evidence to suggest that a variety of caregiver intervention programs, including psychoeducational approaches, positively impact the well-being of the caregiver and the person living with dementia [7-17]. Caregiver education programs have been shown to reduce aspects of caregiver burden [10, 18, 19], distress [20], depression [12, 13, 15, $21,22]$, and stress $[19,23]$, and to improve role positivity [20, 24], confidence [24-26], and health behaviors among participating caregivers [10]. In addition, caregiver education programs can improve self-efficacy. Higher caregiver self-efficacy is associated with better health outcomes, more positive valuation of caregiver duties, and decreased caregiver strain and depressive symptoms [10, 22, 25, 27-29]. While confidence and self-efficacy are related, confidence applies to a caregiver's more global assessment of how well-prepared they feel to handle various aspects of managing care. Self-efficacy measures their ability to perform specific tasks in defined situations [30]. For caregivers of people with dementia, confidence in managing symptoms and self-efficacy related to dementia-related behaviors are particularly relevant. Dementia-related behavioral and psychological symptoms (BPSD) are a principal source of stress in caregivers $[3,31,32]$.

The progressive loss of cognitive skills and decisional capacity that accompanies most forms of dementia forces reliance upon a caregiver to serve as a proxy for learning disease management skills. Dementia is unique in the scope and chronicity of demands it places upon family caregivers, creating significant need for tailored education, training, and support to build confidence, competence, and self-care skills. The majority of persons living with dementia will experience behavioral and psychological symptoms that are a major source of stress for caregivers [31]. Access to psychoeducational programs that promote understanding of dementia, increase confidence in sign and symptom management, and build caregiver skills for nonpharmacologic management of BPSD is needed [4, $13,33]$.

A psychoeducational intervention involves a systematic, structured, and didactic knowledge transfer for an illness and its treatment, integrating emotional and motivational aspects to enable persons to cope with the illness and to improve management skills. Psychoeducation is led by trained professionals and includes structured programs, lectures, discussion, and written materials. Caregiver psychoeducation can positively impact a caregiver's mood, quality of life, mastery, and communication skills $[4,16]$. Successful multi-component dementia care programs often include evidence-based and evidence-informed psychoeducational components in their models [22, 34-36]. However, in-person programs can exacerbate the stress on care providers by requiring their absence from the care environment and travel, and have become extremely challenging during the COVID-19 pandemic. One preliminary study of this pandemic's impact on dementia caregivers suggests a plurality of caregivers had changes in their responsibilities and abilities during COVID-19 and a sizable proportion also reported poor well-being [37]. Effective virtual learning programs have the potential to ameliorate those stressors upon burdened care providers, and to be more convenient and accessible. Limited but emerging evidence suggests that positive dementia caregiver effects can be maintained with transition of non-pharmacological psychoeducation interventions to a virtual delivery format $[12$, 38-41].

Therefore, we set out to ask 1) if adapting an existing, community-based psychoeducational program to a virtual format would be efficacious based on wellaccepted instruments, and 2) whether the program's efficacy would be sustained over time. The purpose of this evaluation was to assess the impact of a fiveweek, interactive virtual caregiver education program on caregiver confidence, self-efficacy, and burden in the community setting. We hypothesized that caregivers participating in the intervention would have significant improvements in all three outcomes compared to controls at both follow-up time points and that perceived impacts would be similar to previous courses. 


\section{MATERIALS AND METHODS}

\section{Study participants}

This study evaluated a caregiver education program developed by MemoryCare, a communitybased non-profit organization in Asheville, North Carolina, that delivers outpatient medical and care management for people with Alzheimer's disease and other types of dementia [42]. The synchronous, virtual program was advertised to caregivers of people with dementia in the Western North Carolina region and was available free of charge to any interested community members from March through December 2020. We recruited caregivers through MemoryCare's existing caregiver mailing list and website announcements. Flyers announcing the program were also sent out through local agencies that serve older adults, people with dementia, and caregivers. These are the same recruitment strategies that were typically used to recruit for the in-person course. All registrants were eligible in consecutive order until classes reached capacity. Controls were people who had participated in a caregiver education event (other than the program being studied). We mailed the initial survey to 346 people inviting them to serve as controls if they could confirm that they were still active family caregivers at the time of the survey. Non-responders received a follow-up email and phone call. If they responded that they intended to serve as a control but did not return the survey, they were contacted one additional time by telephone. Estimated sample size to detect a $20 \%$ difference in burden between intervention and control groups was 65 participants in each group (assuming a mean burden score of 20 and 16 with a standard deviation of 10) [19]. We used burden to determine sample size since it changes less often in studies of caregiver interventions than other caregiver outcomes [38]. We did not randomly assign potential participants to the intervention or control group because this was an existing community-based program that aimed to provide caregivers with education as quickly as possible and assigning potential participants to a waitlist control was deemed to be inconsistent with the organization's mission.

This evaluation was reviewed by Appalachian State University's IRB and considered to not meet the definition of human subjects research since it was an evaluation of an existing program adapted to virtual format (\#20-0220). Participants therefore did not complete informed consent. When intervention or control subjects were sent surveys, they were told the purpose was to evaluate the virtual Caregiver Education Program and that they could choose to skip any questions or not complete the surveys at all.

\section{Intervention: Caregiver training/education program}

In response to expressed needs of caregivers of people with neurocognitive disorders, a team of physicians and care managers developed a five-week Caregiver Education Program in 2008. The program has been taught live a minimum of three times a year since then to over 1,900 caregivers. The course is annually updated for scientific content and caregiver needs.

The core content of MemoryCare's Caregiver Education Program is a series of interactive sessions designed to provide education and support to family caregivers. Each module includes a weekly threehour session with a didactic portion and facilitated discussion. Weekly topics are: 1) What is dementia?, 2) Transitioning from independence to interdependence, 3) Functional and behavioral changes of dementia, 4) Dementia treatment options and risk reduction, and 5) Maintaining your own health. The course addresses the caregiver role in these areas: assessing safety issues, when and how to assist with instrumental and basic activities of daily living (ADLs) at all stages, managing dementia-related behaviors, caregiver self-care and stress management, improving communication techniques and engaging activities, managing health issues and advocating for a person with dementia in the health care system, choosing the best environment for care, accessing community supports, and end-of-life issues. Sessions one through four are led by a physician or advanced practice clinician and session five by a caregiver support specialist. Caregivers share their personal stories and solutions to the problems they face in their roles. Caregivers are given digital manuals with slide sets and links to widely available resources for additional information and new resources are added weekly in response to caregiver needs through expressed questions and electronic queries. There is no systematic follow-up with caregivers after the end of the course; caregivers keep digital materials for future reference.

Originally delivered in person, the virtual Caregiver Education Program was delivered as an entirely synchronous, virtual program via Zoom Video Conferencing, Inc. (Hauppauge, NY) during the COVID-19 pandemic. The course content did 
not change substantially from 2019-2020; the only updates were based on changes in scientific knowledge.

\section{Measures}

Pre- and post-program surveys were developed based on aspects addressed in the course and used three existing measures with demonstrated validity and reliability along with questions developed for the evaluation. The pre- and post-surveys for both the intervention and control groups appear in Supplementary Table 1. Caregivers (in intervention and control groups) self-reported all information via selfadministered paper-and-pencil surveys. Caregiver confidence was measured using five items related to the caregiver's ability to take care of dementia and non-dementia related symptoms from Piggott et al.'s Caregiver Confidence in Sign/Symptom Management scale [43]. Caregivers rated their confidence in their ability to take care of their relative's dementiarelated behaviors, mood changes, mental status changes, new medical problems, and problems associated with ongoing chronic diseases on a scale of not at all confident (1) to extremely confident (5). Scores were summed and higher scores indicated more confidence.

Self-efficacy for managing dementia-related behaviors was assessed using the subscale from the revised scale for caregiver self-efficacy developed by Steffen et al. [44]. Caregivers rated how confident they were in their ability to do a task on a scale of 0 to 100 where 0 meant they could not do it, $50 \%$ meant that with their best effort they had a 50-50 chance of doing it, and $100 \%$ meant they were certain they could do it. Scores were summed then divided by five so the self-efficacy subscale score ranged from 0 to 100 with higher scores reflecting greater self-efficacy.

The twelve-item version of the Zarit Burden Interview developed by Bédard and colleagues measured caregiver burden [45]. Caregivers reported how often they felt things like stress, or uncertainty about what to do. Response options ranged from never (0) to nearly always (4) and scores were summed with higher scores indicating greater burden.

In addition to these outcome measures, surveys collected information about caregivers and care recipients using items from the Behavioral Risk Factor Surveillance System Caregiver Module [46] and the National Alliance for Caregiving's Caregiving in the U.S. survey [47]. These items asked about the caregiver's relationship to the care recipient, whether they lived together, the amount and types of care they typically provided, how long they had provided care, and whether or not they were the primary caregiver. Surveys also collected information about the caregiver's age, sex, race, and Hispanic ethnicity. We collapsed age into two categories based on the distribution among participants: under 65 years and 65 years or older. Controls completed a survey that was identical to the pre-survey for program participants at two points, an average of six weeks apart.

The post-survey included the same questions as the pre-survey plus several program-created items to assess participants' perceptions of the program's impact on 1) their knowledge about cognitive disorders, 2) their confidence as a caregiver, and 3) their ability to manage problem behaviors. Respondents reported whether or not the virtual Caregiver Education Program had increased or improved each of these (yes or no). We compared the study period results to those from caregivers who had taken the in-person program during calendar year 2019 as a secondary measure of program efficacy. At the end of the postsurvey, respondents were given space to respond to the following prompt: Please list changes you have made or experienced as a result of the Caregiver Education Program.

\section{Statistical analysis}

To be included in the main analyses, intervention participants had to be current caregivers aged 18 or older who completed the baseline survey, at least four of five sessions in the five-week caregiver education program, and both follow-up surveys. Controls had to be current caregivers aged 18 or older who completed the baseline and follow-up survey. A complete survey was defined as one with sufficient information to calculate the three main outcome measures: caregiver confidence, self-efficacy, and burden. For each outcome measure, participants had to answer at least $75 \%$ of the items to have the summary score calculated. In primary analyses, we included only participants who completed both follow-up surveys in order to understand the impact on people who completed the course and to limit bias that might arise as a result of people choosing not to do the final survey if they felt the program had not made a lasting impact on them. This decision was made a priori. As a sensitivity analysis, and to account for bias arising from people stopping the course early because it had no impact on them, we used an intent-to-treat approach in which we repeated our main analyses including 
all data collected from all participants, regardless of whether they completed the course or follow-up surveys.

Sample characteristics were described by calculating means and standard deviations for quantitative (discrete/continuous) variables, and frequencies and 95\% confidence intervals for categorical variables. Intervention and control group caregivers were compared using chi-square tests. Pre- and post-survey scores were compared using paired $t$-tests to account for the repeated measures within participants. We used generalized estimating equations (GEE) to compare intervention and control groups over time, to account for correlation between observations, and to adjust for potential confounding variables [48]. We ran separate models for each outcome (i.e., confidence, self-efficacy, and burden). In the crude GEE models, we included only intervention, time, and intervention*time variables. The intervention*time variable was the primary measure of interest; a significant estimate indicates an effect of participating in the virtual Caregiver Education Program on caregiver confidence, self-efficacy, or burden. We also ran adjusted GEE models that included variables to indicate caregiver age group, caregiver sex, relationship between the caregiver and person with dementia, caregiver and care recipient cohabitation, duration and frequency of caregiving provided, and whether the care recipient was enrolled in another dementia program through the organization. The control variables were selected based on a causal diagram. Differences in perceived impact between study participants (2020) and previous in-person course participants (2019) were compared using chi-square tests.

We did not formally conduct a qualitative analysis of the free text responses, but three authors read all comments, summarized them individually, and discussed their relevance to the three main evaluation outcomes: confidence, self-efficacy, and burden. We were interested in learning whether caregivers perceived changes in these domains based on their comments and in identifying what types of changes occurred during the course.

\section{Sample}

During the evaluation period, 151 people enrolled in the caregiver course and completed a baseline survey; seven of these participants were not current caregivers and were excluded from all analyses. Of 346 potential controls contacted to participate, 80 returned a baseline survey. Main analyses included 90 intervention and 44 control caregivers with complete data. Sensitivity analyses included all 224 caregivers enrolled in the study (144 intervention and 80 control group members), regardless of course completion or follow-up data. Figure 1 shows the process by which intervention and control group caregivers were excluded. Differences between included and excluded participants were compared using chisquare tests. All analyses were completed using Stata, version 13.1 (StataCorp, College Station, TX).

\section{RESULTS}

\section{Sample characteristics}

Caregivers in the intervention group were primarily age 65 or older $(53 \%)$, female (74\%), white (99\%), and non-Hispanic (98\%; Table 1). Most often, participants were caring for a spouse or partner $(49 \%)$, living with the care recipient $(62 \%)$, and considered themselves the primary caregiver $(68 \%)$. About three in ten had provided care for at least 2 years (31\%) and averaged 40 hours of care or more per week $(29 \%)$. There were no significant differences in demographic or caregiving characteristics between intervention and control groups. There also were no statistically significant differences between included and excluded intervention group caregivers (Supplementary Table 2).

\section{Primary outcomes}

At baseline, confidence, self-efficacy, and burden scores were all moderate, on average, across participants with relatively high variability (Fig. 2). Controls had higher confidence and self-efficacy and lower burden than intervention caregivers at baseline. At the end of the course, caregiver confidence increased by 2.4 points $(p<0.001)$, and caregiver self-efficacy increased by 4.3 points $(p=0.004)$, on average, among the intervention group (Table 2). These gains were sustained at the 3-month follow-up (confidence: 2.9 points, $p<0.001$; self-efficacy: 6.2 points, $p<0.001)$. Among controls, there was no significant change in confidence or self-efficacy between baseline and 6 weeks. There were no significant differences in caregiver burden at follow-up for either group (intervention group: $0.5, p=0.30$ at 6 weeks and $-0.01, p=0.98$ at three months; control group: $0.7, p=0.44$ at 6 weeks). 
Intervention Group

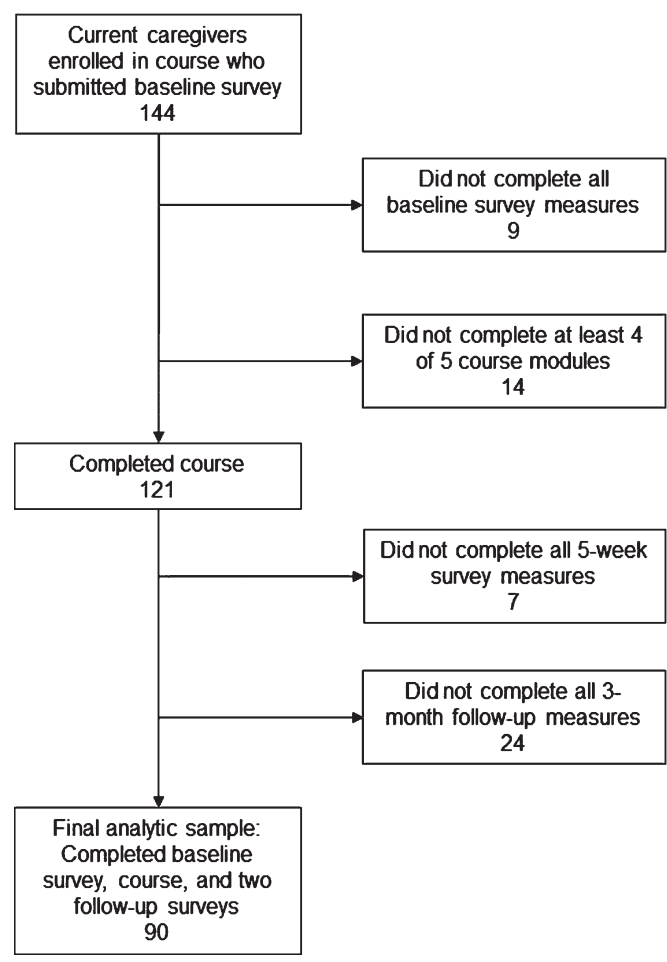

Control Group

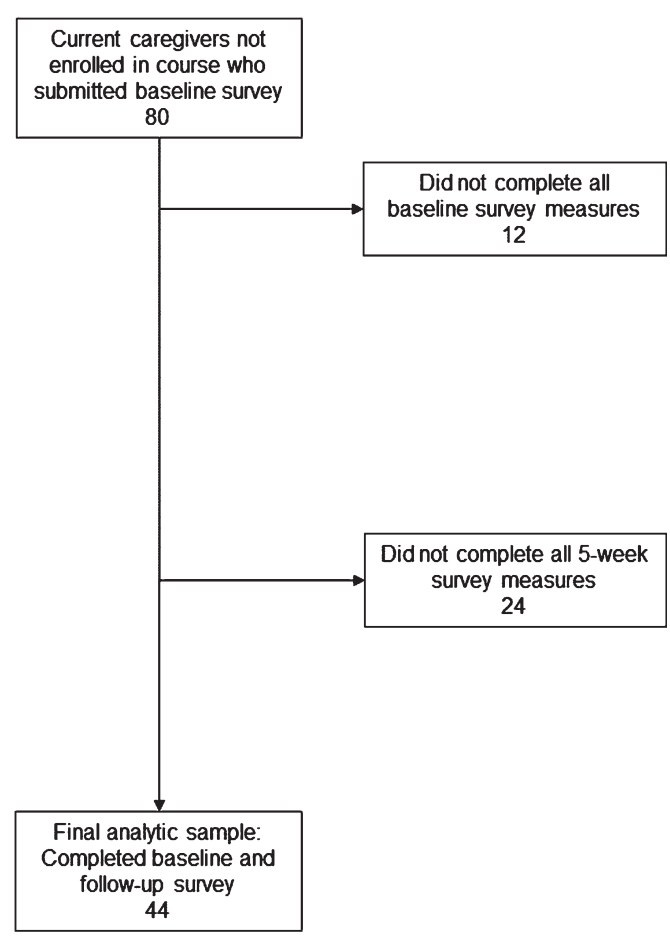

Fig. 1. Flowchart showing reasons for exclusion among of caregivers of people with dementia/other memory disorders who participated in the virtual MemoryCare Caregiver Education Program, March-December, 2020.

Based on crude and adjusted GEE models, participating in the course significantly improved caregiver confidence and self-efficacy compared to controls (intervention*time term in adjusted confidence model: $p=0.013$ at six weeks, $p=0.003$ at three months; intervention*time term in adjusted selfefficacy model: $p<0.001$ at six weeks and three months; Table 3 ). There were no significant differences in burden between the intervention and control groups over follow-up. Results were consistent in both crude and adjusted models. Results were also similar in the main and sensitivity analyses (Supplementary Table 3).

\section{Secondary outcomes}

In the intervention group, all caregivers (100\%) who answered the supplemental questions $(n=87)$ reported perceived increases in their knowledge, 97\% perceived increases in confidence, and $95 \%$ perceived increases in their ability to manage dementia-related behaviors at the end of the program (Supplementary Figure 1). These were similar to or better than results from 2019 in-person sessions (2019: $n=88$ in-person participants; $97 \%, 89 \%$, and $77 \%$ perceived increases in knowledge, confidence, and management ability; $p=0.08,0.05$, and 0.001 , for 2020 versus 2019, respectively). Additionally, among the study group, $98 \%$ perceived that the virtual Caregiver Education Program had a positive impact on their ability to manage caregiver-related stress. This question was not asked in prior years so data were not available for comparison. All participants (100\%) from the inperson and the virtual courses reported they would recommend the program to others.

Based on free-text responses, some caregivers did experience changes in all three outcome domains. Examples of increased confidence include statements about knowing they (the caregiver) are doing the right thing and that they are prepared to handle new symptoms that may arise. Examples of improved selfefficacy include caregivers reporting having more patience, learning new skills, especially in communicating with their care recipient and managing challenging behaviors. Examples of reduced burden include caregivers feeling less stress, engaging in more self-care and feeling less guilt about taking time for self-care, feeling like the care they provide is 
Table 1

Characteristics of caregivers of people with dementia/other memory disorders who participated in the virtual MemoryCare Caregiver Education Program (intervention group) and the control group, March-December, 2020

\begin{tabular}{|c|c|c|c|c|}
\hline Variable & Category & $\begin{array}{l}\text { Intervention } \\
\text { group } \\
(n=90) \\
n(\%)\end{array}$ & $\begin{array}{l}\text { Control group } \\
\qquad(n=44) \\
n(\%)\end{array}$ & $\begin{array}{c}p \text { for } \\
\text { difference }^{1}\end{array}$ \\
\hline \multirow[t]{3}{*}{ Age (years) } & $18-44$ & $5(5.6)$ & $4(9.1)$ & 0.43 \\
\hline & $45-64$ & $32(35.6)$ & $19(43.2)$ & \\
\hline & $65+$ & $53(58.9)$ & $21(47.7)$ & \\
\hline \multirow[t]{2}{*}{ Sex } & Female & $67(74.4)$ & $29(65.9)$ & 0.30 \\
\hline & Male & $23(25.6)$ & $15(34.1)$ & \\
\hline \multirow{2}{*}{$\begin{array}{l}\text { Hispanic, Latino/a, or Spanish } \\
\text { ethnicity }\end{array}$} & Yes & $2(2.2)$ & $1(2.3)$ & 0.99 \\
\hline & No & $88(97.8)$ & $43(97.7)$ & \\
\hline \multirow[t]{3}{*}{ Race } & $\begin{array}{l}\text { Non-white (Black or African American, American } \\
\text { Indian or Alaska Native, Asian, Pacific Islander, or } \\
\text { Other) }\end{array}$ & $1(1.1)$ & $0(0)$ & 0.53 \\
\hline & White & $89(98.9)$ & $36(81.8)$ & \\
\hline & Missing & $0(0)$ & $8(18.2)$ & - \\
\hline \multirow{3}{*}{$\begin{array}{l}\text { Caregiver (CG) is providing care for } \\
\text { their... }\end{array}$} & Parent, including in-law & $39(43.3)$ & $20(45.5)$ & 0.95 \\
\hline & Spouse or partner & $44(48.9)$ & $20(45.5)$ & \\
\hline & Other relative & $7(7.8)$ & $4(9.1)$ & \\
\hline \multirow[t]{5}{*}{ Care recipient lives... } & With caregiver & $56(62.2)$ & $23(52.3)$ & 0.26 \\
\hline & Within 20 min of CG & $20(22.2)$ & $15(34.1)$ & \\
\hline & $20 \mathrm{~min}$ to $1 \mathrm{~h}$ away from $\mathrm{CG}$ & $5(5.6)$ & $2(4.6)$ & \\
\hline & $>1$ hour away & $7(7.8)$ & $1(2.3)$ & \\
\hline & Other & $2(2.2)$ & $3(6.8)$ & \\
\hline \multirow[t]{5}{*}{ Caregiving duration } & $<6$ months & $17(18.9)$ & $2(4.6)$ & 0.07 \\
\hline & 6 months to $<2 y$ & $43(47.8)$ & $20(45.5)$ & \\
\hline & 2 to $<5 y$ & $18(20.0)$ & $15(34.1)$ & \\
\hline & 5 years or longer & $10(11.1)$ & $7(15.9)$ & \\
\hline & Missing & $2(2.2)$ & $0(0)$ & - \\
\hline \multirow{5}{*}{$\begin{array}{l}\text { Amount of caregiving in an average } \\
\text { week }\end{array}$} & Up to $8 \mathrm{~h}$ & $38(42.2)$ & $20(45.5)$ & 0.67 \\
\hline & $9-19 \mathrm{~h}$ & $20(22.2)$ & $10(22.7)$ & \\
\hline & $20-39 \mathrm{~h}$ & $4(4.4)$ & $4(9.1)$ & \\
\hline & $40 \mathrm{~h}$ or more & $26(28.9)$ & $10(22.7)$ & \\
\hline & Missing & $2(2.2)$ & 0 & - \\
\hline \multirow[t]{4}{*}{ Participant is primary caregiver } & Yes & $61(67.8)$ & $34(77.3)$ & 0.38 \\
\hline & Split care evenly with someone else & $12(13.3)$ & $5(11.4)$ & \\
\hline & No, someone else is primary & $16(17.8)$ & $4(9.1)$ & \\
\hline & Missing & $1(1.1)$ & $1(2.3)$ & - \\
\hline
\end{tabular}

${ }^{1} p$-value from chi-square test comparing caregivers in the intervention and control groups, excluding the "missing" category.

high quality, and seeking out additional help or making changes to their routines/work schedules to make caregiving more manageable.

\section{DISCUSSION}

As hypothesized, participating in this five-week, synchronous, virtual Caregiver Education Program improved confidence related to sign recognition and symptom management and self-efficacy related to management of dementia-related behaviors among caregivers of people living with dementia. These improvements were sustained for at least three months. Participants expressed a high level of perceived gains, comparable to prior in-person courses.
The transition to a virtual format was forced by the pandemic, but the positive impact on caregiver confidence and self-efficacy and the high level of acceptability to learners will have enduring value to inform future virtual caregiver education programs and sustain offering them in our rural region.

Contrary to our hypothesis, this intervention did not impact caregiver burden. Other studies of psychoeducational interventions have shown variable impact on caregiver burden [12, 16, 49]. The trajectory of caregiver burden varies in longitudinal studies. Multiple factors impact measurement including: the severity, type, and duration of behavioral symptoms; stage of dementia; use of support services such as day programs or in-home and facility care; caregiver relationship; duration of and number of hours spent 
Intervention

(a)
Control

Baseline $\square 6$ week

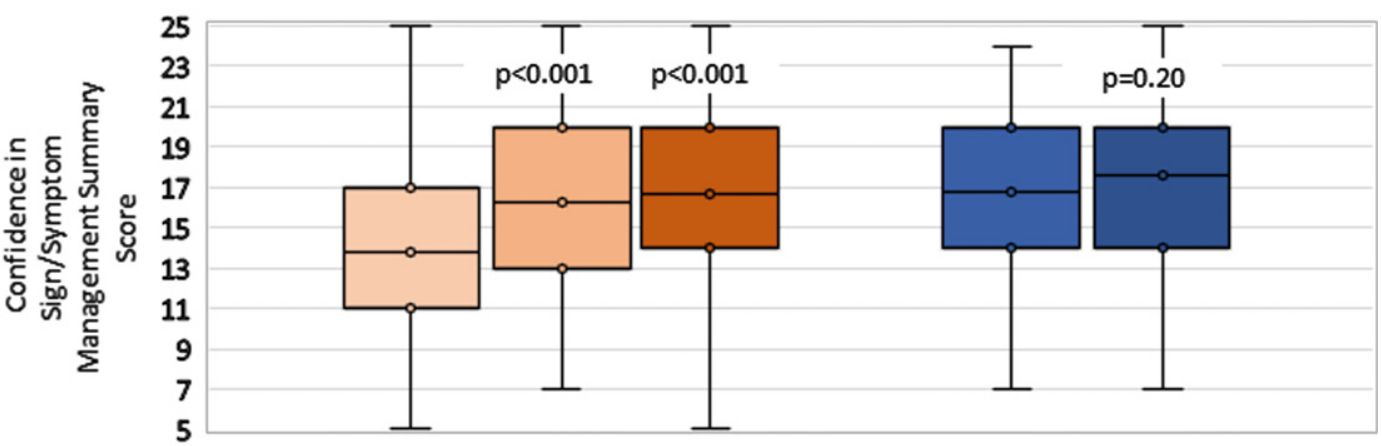

(b)

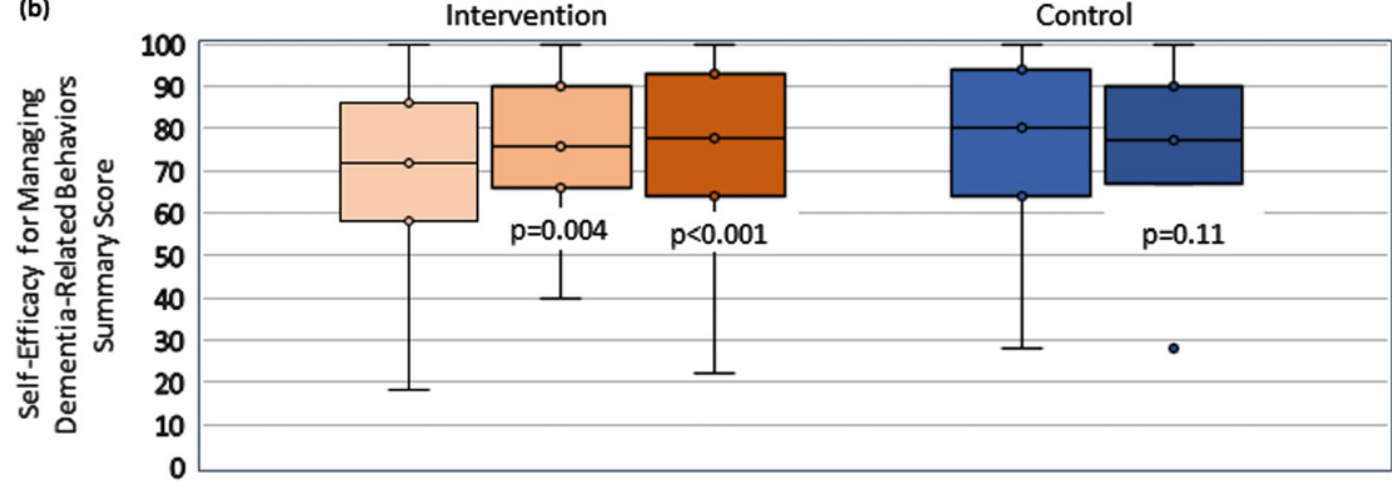

(c)

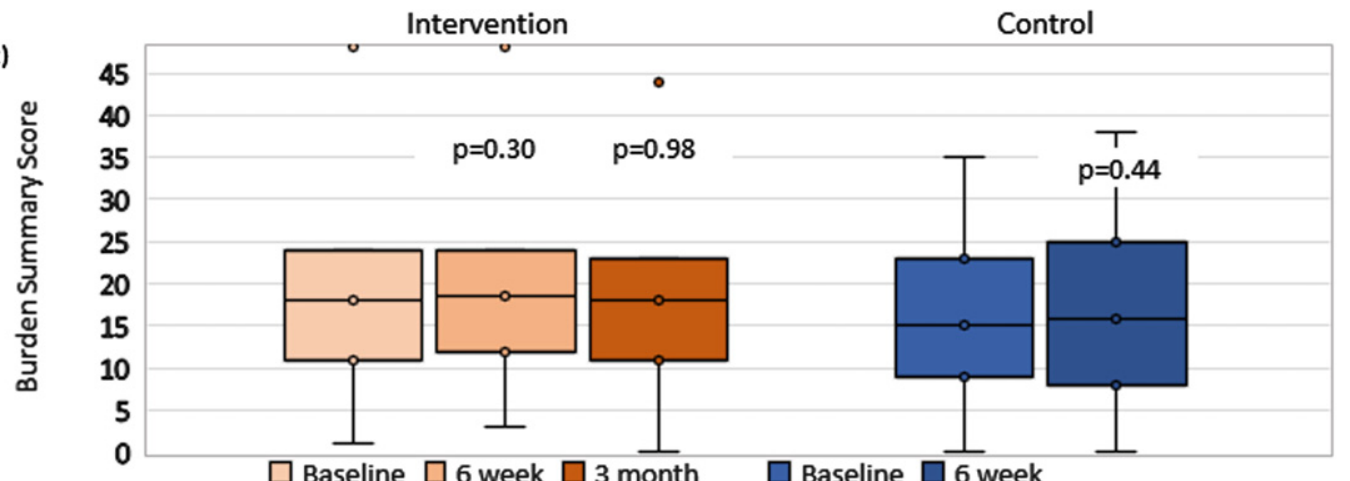

Fig. 2. Distribution of pre- and post-survey scores ${ }^{1}$ for outcome measures for caregivers of people with dementia/other memory disorders who participated in the virtual MemoryCare Caregiver Education Program (intervention group, $n=90$, orange bars) and who did not (control group, $n=44$, blue bars), March-December, 2020. ${ }^{1}$ Higher scores indicate higher confidence (range: 5-25), self-efficacy (range: 0-100), and burden (range: $0-48$ ). Int, intervention group. $p$-values compare the indicated time point to baseline within the same group. For example, in panel (a), the first $p<0.001$ compares the mean 6-week follow-up intervention group score to the baseline intervention group score.

caregiving; level of ADL impairment and health status of the person with dementia and their caregiver; as well as the high level of attrition in studies of caregiver burden $[22,32,50]$. The questions on the Zarit Burden Inventory-12 also reflect areas of burden such as loss of time for self, social activities, and other responsibilities, as well as loss of privacy and control of one's life that are hard realities of a caregiver's burden. This virtual psychoeducational intervention provides practical resources and tools and strongly stresses the importance of self-care and respite. Impact, if present, may take longer than the three-month window of the evaluation to observe, particularly during a pandemic.

This program has the strength of being a detailed, scripted core curriculum with an interactive design 
Table 2

Changes in caregiver confidence, self-efficacy, and burden ${ }^{1}$ from baseline through follow-up among virtual MemoryCare Caregiver Education Program participants and controls, March-December, 2020

\begin{tabular}{|c|c|c|c|c|c|c|c|}
\hline Group & $\begin{array}{c}\text { Baseline } \\
\text { Mean (SD) }\end{array}$ & $\begin{array}{l}\text { 6-week } \\
\text { follow up } \\
\text { (end of } \\
\text { course) } \\
\text { Mean (SD) }\end{array}$ & $\begin{array}{l}\text { Difference: } \\
\text { Baseline to } \\
\text { 6-week } \\
\text { Mean (SD) }\end{array}$ & $\begin{array}{l}p \text {-value for } \\
\text { difference } \\
\text { between } \\
\text { baseline and } \\
6 \text { weeks }\end{array}$ & $\begin{array}{l}\text { 3-month } \\
\text { follow-up } \\
\text { Mean (SD) }\end{array}$ & $\begin{array}{l}\text { Difference: } \\
\text { Baseline to } \\
\text { 3-month } \\
\text { Mean (SD) }\end{array}$ & $\begin{array}{l}p \text {-value for } \\
\text { difference } \\
\text { between } \\
\text { baseline and } \\
3 \text { months }^{2}\end{array}$ \\
\hline \multicolumn{8}{|l|}{ Caregiver Confidence } \\
\hline Intervention $(n=90)$ & $13.8(4.6)$ & $16.3(4.2)$ & $2.4(3.9)$ & $<0.001$ & $16.7(4.7)$ & $2.9(4.0)$ & $<0.001$ \\
\hline Control $(n=44)^{3}$ & $16.8(4.1)$ & $17.6(4.2)$ & $0.8(3.9)$ & 0.20 & Not Collected & & \\
\hline \multicolumn{8}{|l|}{ Caregiver Self-Efficacy } \\
\hline Intervention $(n=90)$ & $71.6(20.0)$ & $75.9(16.1)$ & $4.3(13.7)$ & 0.004 & $77.8(18.3)$ & $6.2(13.3)$ & $<0.001$ \\
\hline Controls $(n=44)^{3}$ & $80.6(17.4)$ & $77.5(18.9)$ & $-3.1(12.5)$ & 0.11 & Not Collected & & \\
\hline \multicolumn{8}{|l|}{ Caregiver Burden } \\
\hline Intervention $(n=90)$ & $18.0(9.4)$ & $18.5(9.1)$ & $0.5(4.9)$ & 0.30 & $18.0(8.4)$ & $-0.01(5.0)$ & 0.98 \\
\hline Controls $(n=44)^{3}$ & $15.2(9.3)$ & $15.9(10.6)$ & $0.7(5.6)$ & 0.44 & Not Collected & & \\
\hline
\end{tabular}

${ }^{1}$ Higher scores indicate higher confidence (range: 5-25), self-efficacy (range: 0-100), and burden (range: 0-48). Bold font indicates statistically significant differences. ${ }^{2} p$-values based on paired $t$-tests. ${ }^{3}$ Controls were only surveyed at the first two time points.

Table 3

Results from generalized estimating equation (GEE) models measuring the association between participation in the virtual MemoryCare Caregiver Education Program (intervention) and changes in caregiver confidence, self-efficacy, and burden ( $n=90$ in intervention group and $n=44$ in control group with data at all three time points)

\begin{tabular}{|c|c|c|c|c|c|c|c|}
\hline \multirow[t]{3}{*}{ Variable } & \multirow[t]{3}{*}{ Category } & \multicolumn{2}{|c|}{ Confidence } & \multicolumn{2}{|c|}{ Self-efficacy } & \multicolumn{2}{|c|}{ Burden } \\
\hline & & $\begin{array}{c}\text { Crude } \\
\text { Coefficient } \\
(95 \% \mathrm{CI})\end{array}$ & $\begin{array}{l}\text { Adjusted } \\
\text { Coefficient } \\
(95 \% \mathrm{CI})\end{array}$ & $\begin{array}{c}\text { Crude } \\
\text { Coefficient } \\
(95 \% \mathrm{CI})\end{array}$ & $\begin{array}{l}\text { Adjusted } \\
\text { Coefficient } \\
(95 \% \mathrm{CI})\end{array}$ & $\begin{array}{c}\text { Crude } \\
\text { Coefficient } \\
(95 \% \mathrm{CI})\end{array}$ & $\begin{array}{c}\text { Adjusted } \\
\text { Coefficient } \\
(95 \% \mathrm{CI})\end{array}$ \\
\hline & & $p$ & $p$ & $p$ & $p$ & $p$ & $p$ \\
\hline \multirow{7}{*}{$\begin{array}{l}\text { Intervention Group* } \\
\text { Time period }\end{array}$} & Intervention* Baseline & Ref & Ref & Ref & Ref & Ref & Ref \\
\hline & Intervention* 6-week & 1.64 & 1.79 & 7.34 & 8.86 & -0.11 & 0.40 \\
\hline & follow-up & $(0.24,3.04)$ & $(0.37,3.21)$ & $(2.71,12.0)$ & (4.13-13.60) & $(-2.04,1.81)$ & $(-1.44,2.25)$ \\
\hline & & 0.022 & 0.013 & 0.002 & $<0.001$ & 0.91 & 0.67 \\
\hline & Intervention* 3 -month & 2.11 & 2.25 & 9.23 & 10.70 & -0.67 & -0.34 \\
\hline & follow-up & $(0.69,3.52)$ & $(0.78,3.71)$ & $(4.65,13.82)$ & $(6.02-15.38)$ & $(-2.60,1.26)$ & $(-2.17,1.50)$ \\
\hline & & 0.004 & 0.003 & $<0.001$ & $<0.001$ & 0.50 & 0.72 \\
\hline \multirow[t]{4}{*}{ Intervention Group } & $\begin{array}{l}\text { No intervention } \\
\text { (Controls) }\end{array}$ & Ref & Ref & Ref & Ref & Ref & Ref \\
\hline & Intervention & -2.97 & -2.91 & -9.00 & -8.23 & 2.75 & 2.58 \\
\hline & & $(-4.50,-1.45)$ & $(-4.42,-1.40)$ & $(-15.56,-2.44)$ & $(-14.40,-2.06)$ & $(-0.59,6.09)$ & $(-0.32,5.47)$ \\
\hline & & $<0.001$ & $<0.001$ & 0.007 & 0.009 & 0.11 & 0.08 \\
\hline \multirow[t]{7}{*}{ Time } & Baseline & Ref & Ref & Ref & Ref & Ref & Ref \\
\hline & 6-week follow-up & 0.77 & 0.68 & -3.06 & -4.54 & 0.66 & 0.37 \\
\hline & & $(-0.37,1.92)$ & $(-0.49,1.86)$ & $(-6.73,0.61)$ & $(-8.25,-0.83)$ & $(-0.97,2.29)$ & $(-1.07,1.81)$ \\
\hline & & 0.19 & 0.26 & 0.10 & 0.02 & 0.43 & 0.62 \\
\hline & 3-month follow-up & 0.77 & 0.68 & -3.06 & -4.54 & 0.66 & 0.37 \\
\hline & & $(-0.37,1.92)$ & $(-0.49,1.86)$ & $(-6.73,0.61)$ & $(-8.25,-0.83)$ & $(-0.97,2.29)$ & $(-1.07,1.81)$ \\
\hline & & 0.19 & 0.26 & 0.10 & 0.02 & 0.43 & 0.62 \\
\hline
\end{tabular}

95\% CI, 95\% Confidence interval for the coefficient; Ref, reference category. Bold numbers indicate statistically significant program effects (group*time variable). "Intervention" refers to caregivers who participated in the 5-week program. Separate GEE models estimated for each of the three outcomes; table represents 6 models total (crude and adjusted for each outcome). All adjusted models included caregiver sex, age (18-64 versus 65 or older), relationship to care recipient (parent, spouse, or other), living with care recipient, caregiving duration $(<6$ months, 6 months- $<2$ years, 2 years- $<5$ years, 5 years or longer), average hours per week of caregiving $(0-8,9-19,20-39,40$ or more), and additional MemoryCare program enrollment (receiving other services for the care recipient).

allowing virtual peer support through group discussion. It was delivered by skilled dementia professionals (clinician and caregiver support specialist), permitting material to be tailored to the specific needs of participants, a valued feature of virtual education in published analyses [38]. The interactive presentation mode of this curriculum provides participants with dementia education, the 
opportunity to learn with and from other participants through sharing questions and stories regarding caregiver roles, and direction to needed resources. The program promotes understanding of the changes that occur in a person with dementia's cognitive and functional abilities, mood, and behavior from the earliest stage to the end of life. Emphasis is placed on learning and respecting the person with dementia's values to be able to serve as an effective advocate as the dyad transitions to interdependence. The virtual format allows caregivers to participate in learning together and facilitates communication with those who live long distance. Additional strengths of this study include its use of validated measures of important caregiver outcomes likely to be influenced by the education program and the external validity of delivery in a real-world setting.

This evaluation demonstrates the utility of a synchronous, virtual caregiver education program in rural areas where it is not feasible to hold in-person sessions. Rural caregivers face unique challenges including lack of specialized dementia health care services, pushing family caregivers to fill the existing service gaps, sometimes for far longer than they are truly capable of providing quality care due to lack of support [51]. The transition to a virtual format allows for wider and more cost-effective dissemination, permitting access to psychoeducational programs to rural caregivers to enhance their ability to provide quality care and support to a family member living with dementia. Indeed, compared to the in-person sessions from 2019, the virtual delivery more often drew attendees from across North Carolina and even from other states. For example, in $2019,61 \%$ of course attendees lived in the county in which the organization is located and $25 \%$ lived in a neighboring county; $1 \%$ lived in a different state. In $2020,46 \%$ of attendees lived in the organization's county, 26\% lived in a neighboring county, and $12 \%$ lived in another state. Eleven new counties in North Carolina were added to the delivery area and nine of those are classified as rural. Access to broadband and computer devices are barriers for some residents in rural areas. However, anecdotally, we observed few concerns about the virtual course, especially after the first few months of the pandemic. Over the 18-month period beginning in March 2020, only six people asked to be placed on a list for the in-person course rather than signing up for the virtual version. Over the evaluation period, we observed dramatic increases in caregivers' comfort with using web conferencing software to complete the course.
Adapting the in-person program increased accessibility to caregivers for whom time away from their care recipient or travel was not possible. Caregivers reported the added value and convenience of being able to take the course without leaving their home or needing to arrange companion care for their care recipient. These features are also likely to appeal to family caregivers of persons living with dementia in non-rural settings. Going forward, we plan to offer both in-person and virtual options along with on-site live streaming at community centers regionally.

The study's generalizability is limited by a homogenous sample reflective of the demographic characteristics of MemoryCare's service region, and the practical challenges of randomly assigning participants to the intervention or control group in an existing community-based program. Further study across caregivers of different racial, ethnic, and cultural backgrounds will be of value and is possible now given the availability of the enduring online resources. Because the intervention was not randomized, our controls had higher confidence and self-efficacy at baseline, on average. There was adequate overlap between the two groups to make comparisons and we do not believe there were ceiling effects in either group. A longer follow-up period would be useful to determine whether, as we hypothesize, changes in burden may occur with more time for participants to integrate changes recommended during the course into their caregiving routines. Also, while the total target sample size of 130 was achieved, it was not equally balanced across intervention and control groups because of difficulty recruiting people into the control arm. This reduced our power, but we were still able to detect differences in confidence and self-efficacy.

A systematic review of internet-based dementia caregiver interventions noted positive trends but called for more high-quality studies to identify effectiveness [38]. Enhanced funding opportunities from national funders for pragmatic, communitybased program evaluations like this one would likely strengthen the evidence base for psychoeducational programs intended to enhance caregiving skills and reduce negative outcomes among caregivers [33]. Caregiver ability to access virtual formats is growing and the scalability, relative cost-effectiveness, and convenience to caregivers whose responsibilities limit their access to in-person education are intrinsic values.

This evaluation builds upon the existing literature base demonstrating that caregiver education 
programs are effective in equipping caregivers to better care for people with Alzheimer's disease or other dementia. This study shows that a synchronous, virtual caregiver education program is effective in improving caregiver confidence and self-efficacy, and that caregivers were as satisfied with it as with a prior in-person version. The program can be readily delivered in community-based, real-world settings. Health systems, health professionals, and public health agencies may consider using pragmatically designed, virtual caregiver education programs to enhance caregiver skills in community-based settings, during emergencies, or in standard practice as an alternative to in-person programs.

\section{ACKNOWLEDGMENTS}

We wish to express appreciation to all evaluation participants and Mary Donnelly, Caregiver Support Specialist, as well as Virginia Templeton, MD, Liz Grieco, Lindsey Kremer, MSW, and David Thomas, MD for their administrative support and/or review of this manuscript. This evaluation was funded, in part, by The Duke Endowment 6851-SP and the Dogwood Health Trust Leverage Fund. Capital expenses for telehealth equipment that enabled virtual delivery was funded by The Cannon Foundation.

Authors' disclosures available online (https:// www.j-alz.com/manuscript-disclosures/21-5359r2).

\section{SUPPLEMENTARY MATERIAL}

The supplementary material is available in the electronic version of this article: https://dx.doi.org/ 10.3233/JAD-215359.

\section{REFERENCES}

[1] World Health Organization, Alzheimer's Disease International (2012) Dementia: A public health priority, World Health Organization, Geneva.

[2] Gitlin LN, Hodgson N (2015) Chapter 17 - Caregivers as therapeutic agents in dementia care: The context of caregiving and the evidence base for interventions. In Family Caregiving in the New Normal, Gaugler JE, Kane RL, eds. Academic Press, San Diego, pp. 305-353.

[3] National Academies of Sciences, Engineering, and Medicine (2016) Families Caring for an Aging America, The National Academies Press, Washington, DC.

[4] Alzheimer's Association (2021) 2021 Alzheimer's Disease Facts and Figures, Alzheimer's Association, Chicago, IL.

[5] Bom J, Bakx P, Schut F, van Doorslaer E (2018) The impact of informal caregiving for older adults on the health of various types of caregivers: A systematic review. Gerontologist 59, e629-e642.
[6] Zhu CW, Scarmeas N, Ornstein K, Albert M, Brandt J, Blacker D, Sano M, Stern Y (2015) Health-care use and cost in dementia caregivers: Longitudinal results from the Predictors Caregiver Study. Alzheimers Dement 11, 444-454.

[7] Cho J, Luk-Jones S, Smith DR, Stevens AB (2019) Evaluation of REACH-TX: A community-based approach to the REACH II Intervention. Innov Aging 3, igz022.

[8] Mittelman MS, Bartels SJ (2014) Translating research into practice: Case study of a community-based dementia caregiver intervention. Health Aff (Millwood) 33, 587-595.

[9] Fauth EB, Jackson MA, Walberg DK, Lee NE, Easom LR, Alston G, Ramos A, Felten K, LaRue A, Mittelman M (2019) External validity of the New York University Caregiver Intervention: Key caregiver outcomes across multiple demonstration projects. J Appl Gerontol 38, 1253-1281.

[10] Lorig K, Ritter PL, Laurent DD, Yank V (2019) Building better caregivers: A pragmatic 12-month trial of a community-based workshop for caregivers of cognitively impaired adults. J Appl Gerontol 38, 1228-1252.

[11] Rosney DM, Noe MF, Horvath PJ (2017) Powerful tools for caregivers, a group psychoeducational skill-building intervention for family caregivers. J Caring Sci 6, 187-198.

[12] Hepburn K, Nocera J, Higgins M, Epps F, Brewster GS, Lindauer A, Morhardt D, Shah R, Nash R, Griffiths PC (2021) Results of a randomized trial testing the efficacy of tele-savvy, an online synchronous/asynchronous psychoeducation program for family caregivers of persons living with dementia. Gerontologist, doi: 10.1093/geront/gnab029.

[13] Maslow K (2012) Translating innovation to impact: Evidence-based interventions to support people with Alzheimer's disease and their caregivers at home and in the community, Alliance for Aging, Washington, DC.

[14] Williams F, Moghaddam N, Ramsden S, De Boos D (2019) Interventions for reducing levels of burden amongst informal carers of persons with dementia in the community. A systematic review and meta-analysis of randomised controlled trials. Aging Ment Health 23, 1629-1642.

[15] Fossey J, Charlesworth G, Fowler J-A, Frangou E, Pimm TJ, Dent J, Ryder J, Robinson A, Kahn R, Aarsland D, Pickett J, Ballard C (2021) Online education and cognitive behavior therapy improve dementia caregivers' mental health: A randomized trial. J Am Med Dir Assoc 22, 1403-1409.e1.

[16] Cheng S-T, Zhang F (2020) A comprehensive meta-review of systematic reviews and meta-analyses on nonpharmacological interventions for informal dementia caregivers. $B M C$ Geriatr 20, 137.

[17] Whitlatch CJ, Orsulic-Jeras S (2018) Meeting the informational, educational, and psychosocial support needs of persons living with dementia and their family caregivers. Gerontologist 58, S58-S73.

[18] Waller A, Dilworth S, Mansfield E, Sanson-Fisher R (2017) Computer and telephone delivered interventions to support caregivers of people with dementia: A systematic review of research output and quality. BMC Geriatr 17, 265.

[19] Lorig K, Thompson-Gallagher D, Traylor L, Ritter PL, Laurent DD, Plant K, Thompson LW, Hahn TJ (2012) Building better caregivers: A pilot online support workshop for family caregivers of cognitively impaired adults. J Appl Gerontol 31, 423-437.

[20] Hepburn K, Lewis M, Tornatore J, Sherman CW, Bremer KL (2007) The Savvy Caregiver program: The demonstrated effectiveness of a transportable dementia caregiver psychoeducation program. J Gerontol Nurs 33, 30-36.

[21] Possin KL, Merrilees JJ, Dulaney S, Bonasera SJ, Chiong W, Lee K, Hooper SM, Allen IE, Braley T, Bernstein A, 
Rosa TD, Harrison K, Begert-Hellings H, Kornak J, Kahn JG, Naasan G, Lanata S, Clark AM, Chodos A, Gearhart R, Ritchie C, Miller BL (2019) Effect of collaborative dementia care via telephone and internet on quality of life, caregiver well-being, and health care use: The Care Ecosystem Randomized Clinical Trial. JAMA Intern Med 179, 16581667.

[22] Park J, Tolea MI, Arcay V, Lopes Y, Galvin JE (2019) Selfefficacy and social support for psychological well-being of family caregivers of care recipients with dementia with Lewy bodies, Parkinson's disease dementia, or Alzheimer's disease. Soc Work Ment Health 17, 253-278.

[23] Savundranayagam MY, Montgomery RJV, Kosloski K, Little TD (2011) Impact of a psychoeducational program on three types of caregiver burden among spouses. Int J Geriatr Psychiatry 26, 388-396.

[24] Kuhn D, Fulton BR, Edelman P (2003) Powerful tools for caregivers: Improving self-care and self-efficacy of family caregivers. Alzheimers Care Today 4, 189-200.

[25] Samia LW, Aboueissa A-M, Halloran J, Hepburn K (2014) The Maine Savvy Caregiver Project: Translating an evidence-based dementia family caregiver program within the RE-AIM Framework. J Gerontol Soc Work 57, 640-661.

[26] Kales HC, Kern V, Kim HM, Blazek MC (2020) Moving evidence-informed assessment and management of behavioral and psychological symptoms of dementia into the real world: Training family and staff caregivers in the DICE approach. Am J Geriatr Psychiatry 28, 1248-1255.

[27] Nogales-González C, Romero-Moreno R, Losada A, Márquez-González M, Zarit SH (2015) Moderating effect of self-efficacy on the relation between behavior problems in persons with dementia and the distress they cause in caregivers. Aging Ment Health 19, 1022-1030.

[28] Fortinsky RH, Kercher K, Burant CJ (2002) Measurement and correlates of family caregiver self-efficacy for managing dementia. Aging Ment Health 6, 153-160.

[29] Rabinowitz YG, Mausbach BT, Gallagher-Thompson D (2009) Self-efficacy as a moderator of the relationship between care recipient memory and behavioral problems and caregiver depression in female dementia caregivers. Alzheimer Dis Assoc Disord 23, 389-394.

[30] Bandura A (1977) Self-efficacy: Toward a unifying theory of behavioral change. Psychol Rev 84, 191-215.

[31] Kales HC, Gitlin LN, Lyketsos CG (2015) Assessment and management of behavioral and psychological symptoms of dementia. BMJ 350, h369.

[32] Connors MH, Seeher K, Teixeira-Pinto A, Woodward M, Ames D, Brodaty H (2020) Dementia and caregiver burden: A three-year longitudinal study. Int J Geriatr Psychiatry 35, 250-258.

[33] National Academies of Sciences Engineering, and Medicine (2021) Meeting the Challenge of Caring for Persons Living with Dementia and Their Care Partners and Caregivers: A Way Forward, The National Academies Press, Washington, DC.

[34] LaMantia MA, Alder CA, Callahan CM, Gao S, French DD, Austrom MG, Boustany K, Livin L, Bynagari B, Boustani MA (2015) The Aging Brain Care Medical Home: Preliminary data. J Am Geriatr Soc 63, 1209-1213.

[35] Clevenger CK, Cellar J, Kovaleva M, Medders L, Hepburn K (2018) Integrated Memory Care Clinic: Design, implementation, and initial results. J Am Geriatr Soc 66, 2401-2407.

[36] Reuben DB, Tan ZS, Romero T, Wenger NS, Keeler E, Jennings LA (2019) Patient and caregiver benefit from a comprehensive dementia care program: 1-year results from the UCLA Alzheimer's and Dementia Care Program. $J$ Am Geriatr Soc 67, 2267-2273.

[37] Trivedi R, Suresh M, Risbud R, Humber M, Jacobs J, Thomas S (2020) How are informal caregivers adapting to COVID19? Preliminary results of an online survey. Innov Aging 4, 948-949.

[38] Hopwood J, Walker N, McDonagh L, Rait G, Walters K, Iliffe S, Ross J, Davies N (2018) Internet-based interventions aimed at supporting family caregivers of people with dementia: Systematic review. J Med Internet Res 20, e216.

[39] Blom MM, Zarit SH, Zwaaftink RBMG, Cuijpers P, Pot AM (2015) Effectiveness of an Internet intervention for family caregivers of people with dementia: Results of a randomized controlled trial. PLoS One 10, e0116622.

[40] Griffiths PC, Whitney MK, Kovaleva M, Hepburn K (2016) Development and implementation of tele-savvy for dementia caregivers: A Department of Veterans Affairs clinical demonstration project. Gerontologist 56, 145-154.

[41] Parra-Vidales E, Soto-Pérez F, Perea-Bartolomé MV, Franco-Martín MA, Muñoz-Sánchez JL (2017) Online interventions for caregivers of people with dementia: A systematic review. Actas Esp Psiquiatr 45, 116-126.

[42] Noel MA, Kaluzynski TS, Templeton VH (2017) Quality dementia care. J Appl Gerontol 36, 195-212.

[43] Piggott CA, Zimmerman S, Reed D, Sloane PD (2017) Development and testing of a measure of caregiver confidence in medical sign/symptom management. Am J Alzheimers Dis Other Demen 32, 373-381.

[44] Steffen AM, McKibbin C, Zeiss AM, Gallagher-Thompson D, Bandura A (2002) The revised scale for caregiving selfefficacy reliability and validity studies. J Gerontol Ser B 57, P74-P86.

[45] Bédard M, Molloy DW, Squire L, Dubois S, Lever JA, O'Donnell M (2001) The Zarit Burden Interview: A new short version and screening version. Gerontologist 41, 652-657.

[46] Caregiver Module, BRFSS FAQs, Healthy Brain Initiative, Surveillance, Alzheimer's Disease and Healthy Aging, CDC, https://www.cdc.gov/aging/healthybrain/brfss-faqcaregiver.htm, Last updated August 12, 2020, Accessed on December 3, 2021.

[47] Caregiving in the US 2020 - Appendix A Full Questionnaire, The National Alliance for Caregiving, https://www.care giving.org/wp-content/uploads/2020/05/Appendix-A-Care giving-in-the-United-States-2020.pdf, Last updated May 11, 2020, Accessed on December 3, 2021.

[48] Hubbard AE, Ahern J, Fleischer NL, Van der Laan M, Lippman SA, Jewell N, Bruckner T, Satariano WA (2010) To GEE or not to GEE: Comparing population average and mixed models for estimating the associations between neighborhood risk factors and health. Epidemiology 21, 467-474.

[49] van den Kieboom R, Snaphaan L, Mark R, Bongers I (2020) The trajectory of caregiver burden and risk factors in dementia progression: A systematic review. J Alzheimers Dis 77, 1107-1115.

[50] Cheng S-T (2017) Dementia caregiver burden: A research update and critical analysis. Curr Psychiatry Rep 19, 64.

[51] Talley RC, Chwalisz K, Buckwalter KC (2011) Rural Caregiving in the United States: Research, Practice, Policy, Springer Science \& Business Media. 